\title{
HOW TO MEASURE PATIENT SAFETY CULTURE? A LITERATURE REVIEW OF INSTRUMENTS
}

\author{
BARTONICKOVA D ${ }^{1,2}$, KALANKOVA $\mathrm{D}^{1}$, ZIAKOVA $\mathrm{K}^{1}$ \\ ${ }^{1}$ Department of Nursing, Jessenius Faculty of Medicine in Martin, \\ Comenius University in Bratislava, Slovak Republic \\ ${ }^{2}$ Department of Nursing, Faculty of Health Sciences, Palacký University in Olomouc, \\ Czech Republic
}

\begin{abstract}
A b s tract
Introduction: Patient safety culture is described as employees' shared values, attitudes, and behaviours in a healthcare organization. Its main goal is to improve patient safety. Assessment of patient safety culture in the hospital environment is most often carried out using self-assessment tools. Although several of these tools have been developed, their comprehensive overview is lacking in literature.

Aim: To provide an overview of instruments measuring patient safety culture in a hospital setting.

Methods: The study has a character of a narrative literature review. The search was performed in the scientific databases Scopus, ProQuest, and PubMed in January 2021. The search produced a total of 1,767 studies and was limited to language (English). The search and the retrieval process reflected PRISMA's recommendations. The content analysis method was used in the data synthesis.

Results: We identified 24 tools for assessing the patient safety culture in a hospital setting, of which seven were developed for specific workplaces; others are considered general. Eighteen tools might be utilized by all healthcare professionals within the hospital setting and only three were designated explicitly for nurses. The most commonly used instruments were the Hospital Survey on Patient Culture and the Safety Attitudes Questionnaire.

Conclusion: Assessing a patient safety culture is considered one of the strategies for improving patient safety while increasing care quality. An appropriate tool's choice depends on the target population, the instrument's validity and reliability, and other aspects. Awareness of the various assessment tools can help hospitals choose the one that best suits their circumstances.
\end{abstract}

Keywords: Hospital; Instrument; Nurse; Patient safety culture; Safety climate

\section{INTRODUCTION}

A patient safety culture assessment is important for improving patient safety within healthcare delivery, especially for identifying additional risks and threats before causing a real problem (1). The concept of safety culture represents the organizational culture in which employees want to provide the safest possible healthcare. Effective evaluation of patient safety culture embodies the regular utilization of self-assessment instruments by healthcare professionals. These instruments are constructed to explore patient safety attitudes, identify aspects of care requiring emergent attention, and motivate hospital management to plan strategies targeted at decreasing general risks that threaten patient safety (2). In many countries, patient safety culture assessments are required by accreditation committees. Several instruments were developed to fulfil these requirements (3).

Corresponding author: Mgr. Dominika Kalánková; e-mail: kalankova1@uniba.sk

(C) 2021 Kalankova D. et al.

This work is licensed under the Creative Commons Attribution-NonCommercial-NoDerivs 4.0 License

(https://creativecommons.org/licenses/by-nc-nd/4.0/) 
However, in the Slovak Republic and the Czech Republic conditions, patient safety culture assessments are voluntary and none of the existing instruments was utilized as mandatory in clinical practice. Despite this, healthcare organizations should carefully consider the right choice of an instrument measuring patient safety culture. Nowadays, there are too many instruments measuring patient safety culture and others are being developed. Also, it is not entirely clear which specific tools are available for its utilization. It is not very clear whether any of them can be applied to a particular workplace's conditions. Another issue that needs to be considered is the intended study population. Few instruments are suitable only for nurses as the most prominent group of healthcare professionals. According to the review published within the American context, thirteen instruments were developed for measuring patient safety culture in different settings (4). Recently, a review published by Australian researchers revealed nine instruments that might be used during healthcare organizations' accreditation (5). Both reviews offer valuable information on particular instruments; however, none of these provides a complex overview of instruments that might be used within the hospital setting. Therefore, our study aimed to provide a complex overview of instruments measuring patient safety culture in a hospital setting.

\section{METHODS}

The paper has adopted the design of a narrative literature review. The literature search was performed in three scientific databases - Scopus, ProQuest, and PubMed in January 2021 (from earliest to January 2021). The databases were selected based on their institutional availability. The literature search was carried out using the exact keywords and Boolean operators AND and OR in all databases as follows hospital, instrument, nurse, patient safety culture, safety climate. The search was limited to language (English) and peer-review papers. The search was not limited to a time period. According to the predefined criteria, we included studies that were: a) quantitative empirical papers (validation studies), b) published in peer-review journals, c) written in English language, d) involving nurses, and e) focused on the topic of interest - measuring patient safety culture in a hospital setting. We excluded studies that were: a) qualitative or mixed-method empirical papers and b) editorials, reviews, case studies, discussion papers or protocols, and c) focusing on hospital management. Based on these criteria, the literature search produced 1,767 studies (519 in Scopus, 849 in ProQuest, and 399 in PubMed). Additional six studies were added to the total number of studies based on the manual search of reference lists from included studies. The total of studies included in the analysis was 1,773 . The search and the retrieval process reflected PRISMA's recommendations (Figure 1). The data were systematically retrieved by two independent researchers (DB, DK) within two phases. We used the program Rayyan $\mathrm{BCRI}{ }^{\circledR}$ in both retrieval phases (6). After removing duplicates $(\mathrm{n}=415), 1,358$ papers were analyzed by reading titles, abstracts, and inclusion criteria in the first phase. Within the second phase, we examined a total of 26 studies by reading full texts. An agreement between two independent researchers was achieved, and four papers were excluded for a reason (insufficient information about instruments). A total of twenty-four studies were included in the final analysis. The data from twenty-four studies were extracted by two researchers using a spreadsheet: author, year, country, instrument, number of items, dimensions of patient safety, evaluation description, and intended study population. The synthesis of the data was performed in a narrative and tabular way of processing. The data were analyzed using the summative content analysis method (7). 


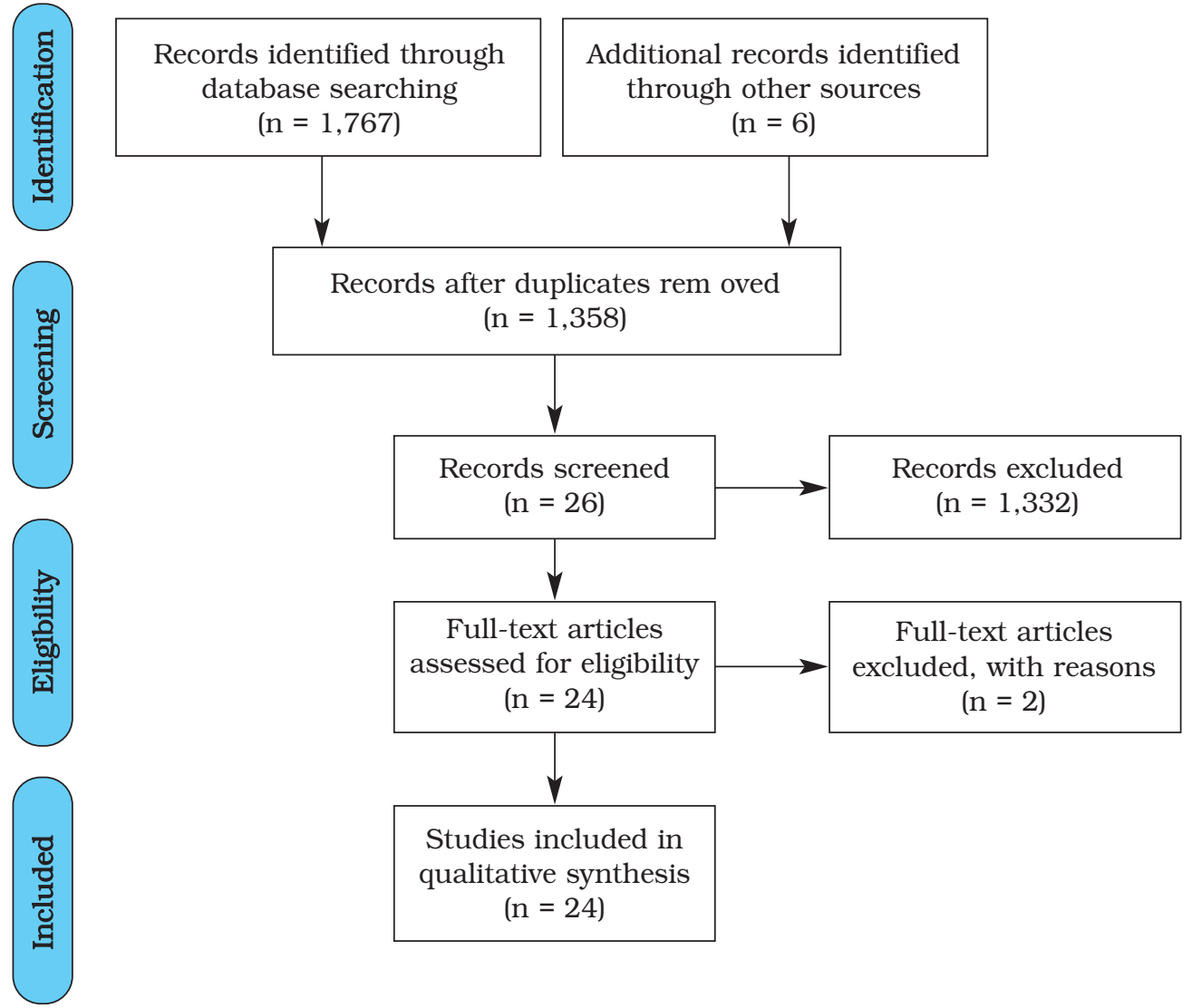

Fig. 1 Flow diagram - recommendation PRISMA

\section{RESULTS}

\section{Survey characteristics}

Twenty-four instruments suitable for utilization in a hospital setting were identified in our review. A significant proportion of studies included in the review were conducted in the USA ( $\mathrm{n}=15 ; 2$ instruments from AHRQ). Studies were also conducted in Australia, Canada, Japan, and in European countries, such as Italy, Germany, and UK. Seventeen instruments are considered general (Table 1) and seven instruments were developed for specific care units (Table 2). Instruments for specific care units were for high-risk hospital areas (12), operating rooms (13), obstetrics care units (14), intensive care units $(17,24)$, acute geriatric units (22), and for any phases of perianesthesia (29). Of all instruments, eighteen might be utilized by all healthcare professionals within the hospital setting and three instruments are suitable for use by nurses $(21,26,29)$, one by physicians, nurses and pharmacists (11), and two by physicians and nurses $(22,27)$.

The number of items ranges from 9 (26) to 128 (22) in the tools mentioned above. For example, the lowest number reflecting dimensions of patient safety culture is 3 in the ShortForm Patient Safety Climate in Healthcare Organisations instrument (9). The individual dimensions in identified instruments covered the important categories reported by Singla et al. (4) as follows: Management/Supervision, Safety system, Risk, Work pressure, Competence, Procedures/Rules, Additional dimensions. The highest number of dimensions is 23, reported in the Patient and Occupational Safety Culture Questionnaire (27), the lowest then 
Table 1 Overview of general instruments measuring patient safety culture in hospital settings

\begin{tabular}{|c|c|c|c|c|}
\hline Author, year, country & Instrument & $\begin{array}{l}\text { Number } \\
\text { of items }\end{array}$ & $\begin{array}{l}\text { Dimensions of } \\
\text { patient safety }\end{array}$ & Evaluation description \\
\hline $\begin{array}{l}\text { Agency for Healthcare } \\
\text { Research and Quality } \\
(1,8) \\
\text { USA }\end{array}$ & $\begin{array}{l}\text { Hospital Survey on Patient } \\
\text { Safety Culture } 1.0 \\
\\
\text { Hospital Survey on Patient } \\
\text { Safety Culture } 2.0\end{array}$ & $\begin{array}{l}42 \\
34\end{array}$ & $\begin{array}{l}12 \\
10\end{array}$ & $\begin{array}{l}\text { 5-point Likert scale; an } \\
\text { open-ended section for } \\
\text { comments. } \\
\text { The same as in version } \\
1.0 \text {. }\end{array}$ \\
\hline $\begin{array}{l}\text { Benzer et al. (9) } \\
\text { USA }\end{array}$ & $\begin{array}{l}\text { Short-form Patient Safety } \\
\text { Climate in Healthcare } \\
\text { Organisations }\end{array}$ & 15 & 3 & Not reported \\
\hline $\begin{array}{l}\text { Ginsburg et al. (10) } \\
\text { Canada }\end{array}$ & $\begin{array}{l}\text { Modified Stanford } \\
\text { Instrument (MSI-06) }\end{array}$ & 32 & 5 & Not reported \\
\hline $\begin{array}{l}\text { Itoh et al. (11) } \\
\text { Japan }\end{array}$ & $\begin{array}{l}\text { Questionnaire-based Survey } \\
\text { of Safety Culture }\end{array}$ & 57 & 9 & 5-point Likert scale \\
\hline $\begin{array}{l}\text { Petschonek et al. (15) } \\
\text { USA }\end{array}$ & Just Culture Assessment Tool & 27 & 6 & 7-point Likert scale \\
\hline Pronovost et al. (16) USA & Safety Climate Scale (SCS) & 10 & Not reported & 5-point Likert scale \\
\hline $\begin{array}{l}\text { Sexton et al. (17) } \\
\text { USA }\end{array}$ & $\begin{array}{l}\text { Safety Attitudes } \\
\text { Questionnaire (SAQ) }\end{array}$ & 60 & 6 & 5-point Likert scale \\
\hline $\begin{array}{l}\text { Sexton et al. (18) } \\
\text { USA }\end{array}$ & $\begin{array}{l}\text { Safety, Communication, } \\
\text { Operational Reliability } \\
\text { and Engagement survey } \\
\text { (SCORE) Survey }\end{array}$ & 48 & 8 & 5-point Likert scale \\
\hline $\begin{array}{l}\text { Singer et al. (19) } \\
\text { USA }\end{array}$ & Stanford/PSCI Culture Survey & 30 & 16 & $\begin{array}{l}\text { 5-point Likert scale; } \\
\text { dichotomous response } \\
\text { options }\end{array}$ \\
\hline $\begin{array}{l}\text { Singer et al. (20) } \\
\text { USA }\end{array}$ & $\begin{array}{l}\text { Patient Safety Climate in } \\
\text { Healthcare Organisations } \\
\text { (PSCHO) }\end{array}$ & 38 & 9 & 5-point Likert scale \\
\hline $\begin{array}{l}\text { Stevanin et al. (21) } \\
\text { Italy }\end{array}$ & $\begin{array}{l}\text { The Multidimensional Nursing } \\
\text { Generations Questionnaire }\end{array}$ & 54 & 8 & 5-point Likert scale \\
\hline Thomas et al. (23) USA & Safety Climate Survey (SCSu) & 21 & Not reported & 5-point Likert scale \\
\hline $\begin{array}{l}\text { Victorian Managed } \\
\text { Insurance Authority } \\
\text { (25) Australia }\end{array}$ & Victorian Safety Climate Scale & 74 & 6 & 5-point Likert scale \\
\hline $\begin{array}{l}\text { Vogus and Sutcliffe } \\
\text { (26) USA }\end{array}$ & The Safety Organizing Scale & 9 & 1 & Not reported \\
\hline $\begin{array}{l}\text { Wagner et al. (27) } \\
\text { Germany }\end{array}$ & $\begin{array}{l}\text { Patient and Occupational } \\
\text { Safety Culture Questionnaire }\end{array}$ & 73 & 23 & 5-point Likert scale \\
\hline $\begin{array}{l}\text { Weingart et al. (28) } \\
\text { USA }\end{array}$ & Culture of Safety Survey & 34 & 5 & $\begin{array}{l}\text { 5-point Likert scale; } \\
\text { dichotomous response } \\
\text { options }\end{array}$ \\
\hline
\end{tabular}


is only one for The Safety Organizing Scale (26). In three instruments there were no identified dimensions (Table 1, 2).

Internal consistency for the identified instruments ranges from 0.50 to 0.94 . However, for most tools, these values have been given for individual dimensions, but not for the whole tool. No internal consistency values were stated for ten instruments (Table 3).

Table 2 Overview of specific instruments measuring patient safety culture in hospital settings

\begin{tabular}{|l|l|l|l|l|}
\hline $\begin{array}{l}\text { Author, year, } \\
\text { country }\end{array}$ & Instrument & $\begin{array}{l}\text { Number } \\
\text { of items }\end{array}$ & $\begin{array}{l}\text { Dimensions of } \\
\text { patient safety }\end{array}$ & Evaluation description \\
\hline $\begin{array}{l}\text { Kaissi et al. (12) } \\
\text { USA }\end{array}$ & $\begin{array}{l}\text { Teamwork and Patient Safety } \\
\text { Attitudes Questionnaire }\end{array}$ & 24 & 4 & 5-point Likert scale \\
\hline $\begin{array}{l}\text { Makary et al. (13) } \\
\text { USA }\end{array}$ & $\begin{array}{l}\text { Safety Attitudes Questionnaire } \\
\text { - Operating room }\end{array}$ & 30 & 6 & 5-point Likert scale \\
\hline Milne et al. (14) UK & Cultural Assessment Survey & 37 & 6 & Not reported \\
\hline $\begin{array}{l}\text { Sexton et al. } \\
\text { (17) } \\
\text { USA }\end{array}$ & $\begin{array}{l}\text { Safety Attitudes Questionnaire } \\
\text { - Intensive Care Units } \\
\text { (SAQ-ICU) }\end{array}$ & 65 & 6 & $\begin{array}{l}\text { 5-point Likert scale, } \\
\text { an open-ended } \\
\text { section for comments. }\end{array}$ \\
\hline $\begin{array}{l}\text { Steyrer et al. (22) } \\
\text { Germany }\end{array}$ & $\begin{array}{l}\text { Patient Safety Culture } \\
\text { Questionnaire }\end{array}$ & 128 & Not reported \\
\hline $\begin{array}{l}\text { Thomas and Lomas } \\
\text { (24) UK }\end{array}$ & $\begin{array}{l}\text { Safety Attitudes Questionnaire } \\
\text { - ICU Short Form }\end{array}$ & 37 & Not reported & 5-point Likert scale \\
\hline $\begin{array}{l}\text { Windle et al. (29) } \\
\text { USA }\end{array}$ & $\begin{array}{l}\text { Perianesthesia Safe Practices } \\
\text { Instrument }\end{array}$ & 65 & & 5-point Likert scale \\
\hline
\end{tabular}

Table 3 Validity and internal consistency through Cronbach`s alpha values for individual instruments

\begin{tabular}{|l|l|l|}
\hline Instrument & $\begin{array}{l}\text { Internal consistency } \\
\text { (Cronbach alpha) }\end{array}$ & Validity \\
\hline Hospital Survey on Patient Safety Culture 1.0 (1) & 0.63 to 0.84 & Construct validity (EFA* -12 factors) \\
\hline Hospital Survey on Patient Safety Culture 2.0 (8) & Not reported & Not reported \\
\hline $\begin{array}{l}\text { Patient Safety Climate in Healthcare Organisations } \\
\text { (20) }\end{array}$ & 0.50 to 0.89 & $\begin{array}{l}\text { Construct validity (EFA }-7 \text { factors; } \\
\text { multitrait analysis }-9 \text { factors) }\end{array}$ \\
\hline $\begin{array}{l}\text { Short-form Patient Safety Climate in Healthcare } \\
\text { Organisations (9) }\end{array}$ & 0.74 to 0.84 & Construct validity (CFA** -3 factors) \\
\hline Stanford/ PSCI Culture Survey (19) & Not reported & Construct validity (EFA -5 factors) \\
\hline Modified Stanford Instrument (10) & 0.81 and 0.88 & Construct validity (EFA -5 factors) \\
\hline Questionnaire-based Survey on Safety Culture (11) & Not reported & Not reported \\
\hline $\begin{array}{l}\text { Teamwork and Patient Safety Attitudes } \\
\text { Guestionnaire (12) }\end{array}$ & 0.62 to 0.87 & Construct validity (EFA -4 factors) \\
\hline Safety Attitudes Questionnaire (17) & 0.90 & Construct validity (CFA - 6 factors) \\
\hline $\begin{array}{l}\text { Safety Attitudes Questionnaire - Intensive Care } \\
\text { Units (17) }\end{array}$ & 0.90 & Construct validity (CFA - 6 factors) \\
\hline
\end{tabular}




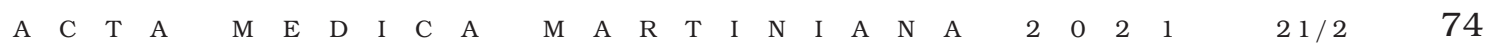

\begin{tabular}{|c|c|c|}
\hline $\begin{array}{l}\text { Safety Attitudes Questionnaire - Intensive } \\
\text { Care Units - Short Form (24) }\end{array}$ & 0.90 & Construct validity (CFA - 6 factors) \\
\hline $\begin{array}{l}\text { Safety Attitudes Questionnaire - Operating } \\
\text { room (13) }\end{array}$ & 0.76 & $\begin{array}{l}\text { Content validity (review of literature, review of } \\
\text { the survey by OR healthcare providers, focus } \\
\text { groups); } \\
\text { construct validity (CFA - } 7 \text { factors) }\end{array}$ \\
\hline Cultural Assessment Survey (14) & 0.72 to 0.84 & $\begin{array}{l}\text { Content validity (review of literature, focus } \\
\text { groups, review of the survey by key informants) }\end{array}$ \\
\hline Just Culture Assessment Tool (15) & 0.63 to 0.86 & $\begin{array}{l}\text { Content validity (review of literature, survey } \\
\text { review); construct validity (CFA - } 7 \text { factors) }\end{array}$ \\
\hline The Safety Climate Scale (16) & 0.68 to 0.81 & Construct validity (CFA - 6 factors) \\
\hline Safety Climate Survey (23) & Not reported & $\begin{array}{l}\text { Content validity (focus groups); construct } \\
\text { validity (single factor structure) }\end{array}$ \\
\hline $\begin{array}{l}\text { Safety, Communication, Operational } \\
\text { Reliability and Engagement survey (18) }\end{array}$ & 0.82 to 0.92 & Not reported \\
\hline $\begin{array}{l}\text { The Multidimensional Nursing Generations } \\
\text { Questionnaire (21) }\end{array}$ & 0.60 to 0.84 & $\begin{array}{l}\text { Face validity (review by nurses); content validi- } \\
\text { ty (review of literature, expert panel); construct } \\
\text { validity } \\
\text { (EFA - } 8 \text { factors) }\end{array}$ \\
\hline The Patient Safety Culture Questionnaire (22) & 0.84 to 0.91 & $\begin{array}{l}\text { Content validity (review of literature, expert } \\
\text { panel); convergent validity (adverse events); } \\
\text { construct validity (EFA - } 7 \text { factors) }\end{array}$ \\
\hline Victorian Safety Climate Scale (25) & Not reported & Not reported \\
\hline The Safety Organizing Scale (26) & 0.88 & $\begin{array}{l}\text { Content validity (review of literature, expert } \\
\text { panel, pretest with a sample of } 45 \text { RNs); con- } \\
\text { struct validity (CFA - single factor structure); } \\
\text { discriminant validity (employee commitment, } \\
\text { trust in manager) }\end{array}$ \\
\hline $\begin{array}{l}\text { Patient and Occupational Safety Culture } \\
\text { Guestionnaire (27) }\end{array}$ & 0.59 to 0.89 & Content validity (expert panel) \\
\hline The Culture of Safety Survey (28) & Not reported & $\begin{array}{l}\text { Face validity (survey review); content validity } \\
\text { (review of literature, focus groups, survey } \\
\text { review) }\end{array}$ \\
\hline Perianesthesia Safe Practices Instrument (29) & 0.79 to 0.94 & $\begin{array}{l}\text { Content validity (review of literature, expert } \\
\text { panel) }\end{array}$ \\
\hline
\end{tabular}

*EFA - exploratory factor analysis; CFA - confirmatory factor analysis 


\section{Development of individual tools}

HSOPS version 1.0 instrument was developed originally by Westat under a contract with AHRQ (1) based on the existing literature review on patient safety culture and a review of two instruments - Veterans Health Administration Patient Safety Questionnaire and the Medical Event Reporting System for Transfusion Medicine. HSOPS version 1.0 has been recently piloted by AHRQ (8) to HSOPS version 2.0, which is recommended instead of the first version.

Patient Safety Climate in Healthcare Organisations was developed by Singer et al. (20) based on five existing instruments. Items from these instruments were modified for use in a hospital setting. In 2017, a short form of Patient Safety Climate in Healthcare Organisations was published by Benzer et al. (9).

Stanford/ PSCI Culture Survey was developed by Singer et al. (19) based on five existing instruments - Management Attitudes Questionnaire, Anesthesia Work Environment Survey, Naval Command Assessment Tool, Risk Management Questionnaire, Safety Orientation in Medical Facilities. However, the instrument was modified to Modified Stanford Instrument (10).

A Questionnaire-based Survey on Safety Culture was developed by Itoh et al. (11) based on adopting four parts of the questionnaire from the Operating Team Resource Management Survey.

Teamwork and Patient Safety Attitudes Questionnaire was developed by Kaissi et al. (12) based on the extraction of items from previous questionnaires and expert opinions of local healthcare leaders and researchers.

Safety Attitudes Questionnaire (SAQ) was developed by Sexton et al. (17) based on the modification of the existing instrument - Intensive Care Unit Management Attitudes Questionnaire (23), which derived from the Flight Management Attitudes Questionnaire, and also discussions with healthcare providers and subject matter experts and two conceptual frameworks: Vincent's framework for analyzing risk and safety (30) and Donabedian's model of quality care (31). The tool was adapted for use in intensive care units (17) and operating rooms (13). Furthermore, the Safety Attitudes Questionnaire - Intensive Care Units was modified by Thomas and Lomas (24) to reflect UK practice concerning job roles and published as Safety Attitudes Questionnaire - Intensive Care Units - Short Form. Safety Attitudes Questionnaire - Operating room was adapted from the original SAQ instrument, and modifications were made based on a literature review on patient safety in the operating rooms, results of the focus groups, and a review of the questionnaire by operating room healthcare provider (13).

Cultural Assessment Survey was developed by Milne et al. (14) based on a literature review on patient safety publications and best practices within the health care environment and key informant interviews with members of the Managing Obstetrical Risk Efficiently Program of the Society of Obstetricians and Gynaecologists.

Just Culture Assessment Tool was developed by Petschonek et al. (15) based on a comprehensive review of the just culture literature and safety culture literature and existing patient safety culture measurements.

The Safety Climate Scale was developed by Pronovost et al. (16) based on the existing instrument - the Flight Management Attitudes and Safety Survey (23).

Safety Climate Survey was developed by Thomas et al. (23) and endorsed by the Institute for Healthcare Improvement based on the items from SAQ.

Safety, Communication, Operational Reliability, and Engagement survey (SCORE) was developed in 2014 by Sexton et al. (18) based on the update of SAQ to reflect contemporary healthcare safety needs.

The Multidimensional Nursing Generations Questionnaire was developed by Stevanin et al. (21) based on a systematic literature review and opinions from an expert panel.

The Patient Safety Culture Questionnaire was developed by Steyrer et al. (22) based on an extensive literature review on instruments measuring patient safety culture and qualitative interviews with health care experts. 
Victorian Safety Climate Scale was developed by the Victorian Managed Insurance Authority (25) based on SAQ items; however, the specific work settings items were replaced with more general ones. As a result, the instrument was more relevant and applicable to Australian hospital settings.

The Safety Organizing Scale was developed by Vogus and Sutcliffe (26) based on a review of case studies of high-reliability organizations (HROs).

Patient and Occupational Safety Culture Questionnaire was developed by Wager et al. (27) based on dimensions from the German version of the HSOPS instrument and SAQ and literature review on occupational safety, including risk and prevention

The culture of Safety Survey was developed by Weingart et al. (28) based on a literature review focusing on safety culture, organizational culture, and high-reliability organizations, as well as on focus groups.

Perianesthesia Safe Practices Instrument was developed by Windle et al. (29) based on a literature review on tools measuring patient safety culture and a review of additional studies.

\section{DISCUSSION}

Creating a culture of patient safety is one of the critical challenges which healthcare organizations are facing nowadays. Recently, many hospitals have begun assessing safety culture and improving the overall quality of provided care. However, they do not often know which tools are available and which one they should choose when choosing (1-3). Therefore, the main aim of our review was to provide an overview of instruments measuring patient safety culture in a hospital setting. In the beginning of January 2021, we identified a total of twenty-four instruments and described their development and psychometric properties. Almost all instruments were developed within the Anglo-American context and only three tools were developed in European countries. However, all of the identified instruments reflect the sociocultural contexts of the Slovak or Czech clinical nursing practices. These instruments are suitable for utilization in both countries, with respect to translations and minor cultural adaptations related mainly to job titles or categories of healthcare personnel. All instruments are designed for a quantitative data processing. Some of these instruments reflect the specific requirements of the environment, respondent or other circumstances. In newly-developed instruments, the number of particular items related to patient safety culture is growing exponentially. Therefore, organizations have an opportunity to choose from a wide range of these instruments. However, selecting an appropriate tool is often not an easy process. The tool should show satisfactory results in a pilot survey of psychometric properties in the organization or country before its implementation in practice (2). Concerning psychometric properties, instruments showed different values of validity and reliability. Data on psychometric properties have not been published in four instruments yet. However, according to the obtained data on most instruments, we may conclude that these are valid and reliable.

Singla et al. (4) conducted the first review and synthesis of the measurement tools related to patient safety. They identified 13 of these instruments, including 657 questions related to patient safety. Most of the recognized instruments were also included in our review. However, the rest of the tools described in Singla's study were only included in unpublished personal communication. We do not consider this method of inclusion of instruments very appropriate. There might be hundreds of tools that have been developed, but their psychometric properties or development process have not been published. Therefore, we analyzed only primary sources in our review. Besides, instruments related exclusively to management were included in Singla's review. On the contrary, we excluded this type of instrument due to its specific focus and the fact they did not consider patient safety culture in general. The review of Singla et al. (4) also identified individual questions and grouped them into 23 dimensions of patient safety culture. A similar num- 
ber of dimensions was reported in a recent questionnaire development study of Wagner et al. (27).

More recently, Hodgen et al. (5) conducted a review focusing on identifying instruments suitable for assessing patient safety culture during the accreditation processes under the Australian Health Service Safety and Quality Accreditation Scheme. Based on their results, none of the instruments was recognized to assess all the safety culture's main components, thus could not be implemented during the accreditation process. On a small sample of hospitals in Australia it has been found that the safety culture is assessed through internal ways (primarily by questionnaires) which are usually designed based on a shortlist of questions from some instruments, such as SAQ. In a review of safety culture assessment tools by Hodgen et al. (5), a total of nine instruments were examined. These instruments were included according to the frequency of their citations, validity, and other established criteria. One of the identified instruments was designated for a qualitative processing and due to its nature not included in our review. The other instruments listed and further analyzed in the study by Hodgen et al. (5), which used quantitative self-report measures, were consistent with these identified in our study.

In terms of the number of studies published in connection with the individual instruments, we may conclude that the most widespread, translated into various languages, and popular among researchers around the world are those reviewed by Sexton et al. (17) - the Safety Attitude Questionnaire (SAQ) and the Hospital Survey on Patient Safety Culture (HSOPS). These instrument have shown acceptable validity and reliability and are highly recommended for use in various sociocultural contexts. Both of them reflect the basic dimensions of patient safety, including teamwork, communication, and management support. The differences between them lie in including issues related to human rights and job satisfaction in the SAQ while involving issues concerning handoffs, transitions, and management support in HSOPS. Regarding the use of these instruments in the Czech Republic and Slovakia, only the HSOPS has been tested on a sample of registered nurses in the Czech and Slovak hospital environment (e.g. 32-35). However, HSOPS questionnaire was validated for the conditions of the Czech nursing practice revealing the same factor structure as original version (32). Recently, the validation study of the HSOPS was also conducted within the Slovak nursing practice; nevertheless indicating the eight factor structure (33). To the authors knowledge, other instrument measuring patient safety culture has not been used within these two countries. Still, based on the results of the studies mentioned above, the evaluation of patient safety culture with this tool seems to be generally acceptable in Czech and Slovak practice conditions. It supports the view of maintaining the uniform assessment structure recommended by AHRQ. Moreover, study results might be comparable among the countries on the international level by using the databases of studies recommended by AHRQ or authors of the SAQ. Even though the SAQ has not been used in the Czech or Slovak conditions but based on the results of psychometric testing of the SAQ, we recommend using both instruments in further studies concerning the patient safety culture assessment.

\section{CONCLUSION}

In our review we identified a total of 24 instruments for assessing the culture of patient safety. The particular tools differ in the number of items, the evaluation of various dimensions, the psychometric characteristics, the target group of respondents, or specific focus to certain workplaces. Nowadays, patient safety is a highly discussed issue internationally, especially its impact on the quality of care. However, we believe that through its regular and repeated assessment, management can focus directly on problematic areas related to patient safety terms. For this assessment, it is vital to determine which instrument will be utilized in the organizations in advance. Awareness of particular instruments and their differences may help organizations choose the one that will suit their circumstances. 


\section{REFERENCES}

1. Sorra JS, Nieva VF. Hospital Survey on Patient Safety Culture [online]. 2004 [cited 2021 Feb 03]. Available on: http://www.ahrq.gov/ sites/default/files/wysiwyg/professionals/quality-patientsafety/patientsafetyculture/hospital/resources/hospcult.pdf

2. Desmedt M, Bergs J, Vertriest S, Vlayen, Schrooten W, Hellings J, Vandijck D. Systematic psychometric review of self-reported instruments to assess patient safety culture in primary care. J Adv Nur 2018; 74(3): 539-549.

3. Theodosios S. The development of patient safety culture. Health Sci J 2012; 6(2): 201-211.

4. Singla AK, Kitch BT, Weissman JS, Campbell EG. Assessing patient safety culture: A review and synthesis of the measurement tools. J Patient Saf 2006; 2(3): 105-115.

5. Hodgen A, Ellis L, Churruca K, Bierbaum M. Safety Culture Assessment in Health Care: A review of the literature on safety culture assessment modes. Sydney: Australian Commission on Safety and Quality in Health Care; 2017.

6. Ouzzani M, Hammady H, Fedorowicz Z, Elmagarmid A. Rayyan - a web and mobile app for systematic reviews. Syst Rev 2016; 5(1): 210.

7. Hsieh HF, Shannon SE. Three approaches to qualitative content analysis. Qual Health Res 2005; 15(9): 1277-1288.

8. Sorra J, Yount N, Famolaro T, Gray L. AHRQ Hospital Survey on Patient Safety Culture Version 2.0: User's Guide [online] 2019. [cited $2021 \mathrm{Feb}$ 03] Available on: https://www.ahrq.gov/sops/surveys/hospital/ index.html.

9. Benzer JK, Meterko M, Singer SJ. The patient safety climate in healthcare organizations (PSCHO) survey: Short-form development. J Eval Clin Pract 2017; 23(4): 853-859.

10. Ginsburg L, Gilin D, Tregunno D, Norton PG, Flemons W, Fleming M. Advancing Measurement of Patient Safety Culture. Health Serv Res 2009; 44(1): 205-224.

11. Itoh K, Abe T, Andersen HB, Kitazawa N (2003). A questionnaire-based survey of safety culture in Japanese hospitals. Korea, Seoul: Proceedings of the 15th Triennial Congress of the International Ergonomics Association; 2003.

12. Kaissi A, Johnson T, Kirschbaum MS. Measuring teamwork and patient safety attitudes of highrisk areas. Nurs Econ 2003; 21(5): 211-218.

13. Makary MA, Sexton JB, Freischlag JA, Holzmueller CG, Millman EA, Rowen L, Pronovost PJ. Operating room teamwork among physicians and nurses: teamwork in the eye of the beholder. J Am Coll Surg 2006; 202(5): 746-752.

14. Milne JK, Bendaly N, Bendaly L, Worsley, J, Fitzgerald J, Nisker J. A measurement tool to assess culture change regarding patient safety in hospital obstetrical units. JOGC 2010; 32(6): 590-597.

15. Petschonek S, Burlison J, Cross C, Martin K, Laver J, Landis RS, Hoffman JM. Development of the Just Culture Assessment Tool. J Patient Saf 2013; 9(4): 190-197.

16. Pronovost PJ. Evaluation of the culture of safety: survey of clinicians and managers in an academic medical center. Qual Saf Health Care 2003; 12(6): 405-410.

17. Sexton JB, Helmreich RL, Neilands TB, Rowan K, Vella K, Boyden J, Roberts PR, Thomas EJ. The Safety Attitudes Questionnaire: psychometric properties, benchmarking data, and emerging research. BMC Health Serv Res 2006; 6(1): 44.

18. Sexton JB, Sharek PJ, Thomas EJ, Gould JB, Nisbet CC, Amspoker AB, Kowalkowski MA, Schwendimann R, Profit J. Exposure to leadership walk rounds in neonatal intensive care units is associated with a better patient safety culture and less caregiver burnout. BMJ Qual Saf 2014; 23(10): 814-822.

19. Singer SJ, Gaba DM, Geppert JJ, Sinaiko AD, Howard SK, Park KC. The culture of safety: results of an organization-wide survey in 15 California hospitals. Qual Saf Health Care 2003; 12(2): 112 118.

20. Singer S, Meterko M, Baker L, Gaba D, Falwell A, Rosen A. Workforce perceptions of hospital safety culture: development and validation of the patient safety climate in Healthcare Organizations Survey. Health Serv Res 2007; 42(5): 1999-2021.

21. Stevanin S, Bressan V, Vehviläinen-Julkunen K, Pagani L, Poletti P, Kvist T. The Multidimensional 
Nursing Generations Questionnaire: development, reliability, and validity assessments. J Nurs Manag 2017; 25(4): 287-296.

22. Steyrer J, Latzke M, Pils K, Vetter E, Strunk G. Development and validation of a Patient Safety Culture Questionnaire in acute geriatric units. Gerontology 2011; 57(6): 481-489.

23. Thomas EJ, Sexton JB, Neilands TB, Frankel A, Helmreich RL. The effect of executive walk rounds on nurse safety climate attitudes: A randomized trial of clinical units. BMC Health Serv Res 2005; $5(1): 28$.

24. Thomas A, Lomas JP. Establishing the use of a safety attitudes questionnaire to assess the safety climate across a critical care network. J Intensive Care Soc 2018; 19(3): 219-225.

25. Victorian Managed Insurance Authority. Safety Climate survey: A staff survey for measuring patient safety. Guidelines for administration. Melbourne: Victoria; 2011.

26. Vogus TJ, Sutcliffe KM. The Safety Organizing Scale: development and validation of a behavioral measure of safety culture in hospital nursing units. Med Care 2007; 45(1): 46-54.

27. Wagner A, Michaelis M, Luntz E, Wittich A, Schrappe M, Lessing C, Rieger, MA. Assessment of patient and occupational safety culture in hospitals: Development of a questionnaire with comparable dimensions and results of a feasibility study in a German University Hospital. Int J Environ Res Public Health 2018; 15(12): 2625.

28. Weingart SN, Farbstein K, Davis RB, Phillips RS. Using a multihospital survey to examine the safety culture. Jt Comm J Qual Patient Saf 2004; 30(3): 125-132.

29. Windle PE, Krenzischek DA, Mamaril M. Development and initial testing of the perianesthesia safe practices instrument: an ASPAN pilot study. J Perianesth Nurs 2007; 22(6): 370-384.

30. Vincent C, Taylor-Adam S, Stanhope N. Framework for analyzing risk and safety in clinical medicine. BMJ 1998; 316(7138): 1154-1157.

31. Donabedian A. The quality of care. How can it be assessed? JAMA 1988; 260(12): 1743-1748.

32. Bartoničková D, Kalánková D, Mikšová Z, Kurucová R, Tomová, Š, Žiaková K. The psychometric properties of „Hospital Survey on Patient Safety Culture“ in a Czech environment. Cent Eur J Nurs Midwifery 2019; 10(3): 1076-1086.

33. Gurková E, Kalánková D, Kurucová R, Žiaková K. Assessment of patient safety climate by nurses in Slovak Public and private hospitals. J Nurs Manag 2020; 28(7): 1644-1652.

34. Kalánková D, Bartoníčková D, Žiaková K, Gurková E, Kurucová R. Assessment of the safety climate at university hospitals in the Slovak Republic from the nurses' perspective. Acta Med Martin 2020; 20(1): 27-38.

35. Sováriová Soósová M, Zamboriová M, Murgová A. Hospital patient safety culture in Slovakia. Ošetrovatel'stvo: teória, výskum, vzdelávanie 2017; 1(1): 12-19.

36. Kalánková D, Bartoníčková D, Gurková E, Žiaková K, Kurucová R. A validation study of the Slovak version of the Hospital Survey on Patient Safety Culture (with Slovak nurses). Cent Eur J Nurs Midwifery 2021; 12(2): 353-365.

Received: June, 6, 2021

Accepted: July, 17, 2021 